\title{
Neuerungen beim
} Thieme ZeitschriftenAbo

Alle Mitglieder, die ein Zeitschriften-Abo haben, werden ab 2016 angeben können, ob Sie ihr Abo rein digital und damit nur noch online oder wie gehabt in Papierform beziehen möchten. Der Thieme Verlag wird dazu eine Website freischalten und den link via Aussendung kommunizieren.

Dieses ist ein Fazit der langen Verhandlungen des ÖGUM-Vorstands und seiner Schwestergesellschaften mit dem Verlag. Aber auch die preisliche Gestaltung des rein digitalen Bezugs wird sich vom Bezug in Papierform unterscheiden. Detaillierte Informationen hierzu finden Sie im Memberbereich. 